\title{
Prebiotic Activity of Polysaccharides Extracted from Jerusalem Artichoke Tuber and Development of Prebiotic Granules
}

\author{
Sakulrat Rattanakiat ${ }^{1, *}$, Pawitra Pulbutr', Wanwisa Khunawattanakul', Bunleu Sungthong', Kritsanee \\ Saramunee ${ }^{1}$
}

\section{Sakulrat Rattanakiat, ${ }^{1 *}$, Pawitra Pulbutr ${ }^{1}$, Wanwisa Khunawattanakul', Bunleu Sungthong ${ }^{1}$, Kritsanee Saramunee ${ }^{1}$}

'Faculty of Pharmacy, Mahasarakham University, Maha Sarakham, 44150 THAILAND.

\section{Correspondence}

Sakulrat Rattanakiat

Faculty of Pharmacy, Mahasarakham University, Maha Sarakham, 44150, THAILAND.

E-mail: sakulrat.r@msu.ac.th History

- Submission Date: 17-06-2020;

- Review completed: 21-07-2020;

- Accepted Date: 03-08-2020.

DOI : 10.5530/pj.2020.12.194

Article Available online

http://www.phcogj.com/v12/i6

\section{Copyright}

(C) 2020 Phcogj.Com. This is an openaccess article distributed under the terms of the Creative Commons Attribution 4.0 International license.

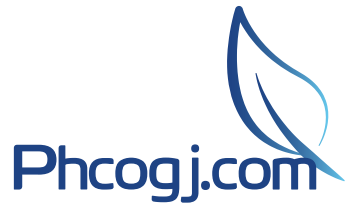

\begin{abstract}
Introduction: Jerusalem artichoke tubers (JA) contain non-digestible carbohydrates, especially inulin-type fructans, which have been found to possess various benefits on human health, including the prebiotic effect. Although many studies established the prebiotic property of inulin or fructo-oligosaccharides, there are less information of the prebiotic potential of JA crude extract. This study aimed to investigate prebiotic effect of the JA extract and develop prebiotic granules from JA extract. Material and Methods: Crude polysaccharide extract of JA was obtained using hot water and freeze-dried method. The selected probiotics, including $L$. plantarum, $L$. acidophilus, $B$. longum and $B$. breve were used in this study. The prebiotic effect of the JA extract was indicated by bacterial growth and acid production. Parallelly, JA extract granule formulation was developed to be a prebiotic food product. Results: The JA extract at the highest concentration tested $(2 \%)$ caused a significant increase in the growth and acid production of every probiotics tested, including L. plantarum, L. acidophilus, B. longum and $B$. breve. The growth promoting effects of the $2 \%$ JA extract were detected as early as 12 hour-incubation, and this action was maintained throughout the observed incubation period. Conclusions: The developed JA extract granules possessed desirable properties with the moisture content of $4.00 \pm 0.20 \%$. The formulated granule was soluble in water and produced a brown and clear solution with slightly sweet taste. Nonetheless, in vivo experiments on the prebiotic effect of the developed preparation should be performed further.
\end{abstract}

Key words: Helianthus tuberosus, Jerusalem artichoke, Prebiotic effect, Granule, Probiotics.

\section{INTRODUCTION}

Jerusalem artichoke (Helianthus tuberosus L.) is a tuberous perennial plant belonging to Compositae family. The edible tubers of Jerusalem artichoke primarily contain inulin, a polysaccharide of fructose polymer linked by $\beta(2 \rightarrow 1)$ linkage with a glucose residue at its end. ${ }^{1}$ Inulin-type fructans cannot be digested by human digestive enzyme. However, it can be fermented by probiotics, especially bifidobacteria and lactobacilli, residing in the large intestine, resulting in a production of short chain fatty acids, which can be used by the bacteria. Prebiotic was defined as a non-digestible dietary components that undergo selective colonic fermentation, causing significant changes in the composition of the gut microflora with increased and decreased numbers of potentially healthpromoting bacteria and potentially harmful species, respectively. ${ }^{2}$ The prebiotic effects of inulin have been demonstrated evidently in various animal and human studies. ${ }^{3,4}$ Various beneficial effects of inulin on human health, including enhancement of host defense mechanism and modulation of the immune system, have been found to be linked with its prebiotic effect. ${ }^{5-7}$ Additionally, since it is a dietary fiber, inulin also provide other healthpromoting effects such as reduction of plasma lipid, induction of body weight loss, improvement of insulin sensitivity and decrease risk of diabetes mellitus. $^{8-10}$
The inulin content of Jerusalem artichoke tubers was reported to be ranged from 7 to $30 \%$ of its fresh weight. ${ }^{11,12}$ It has been demonstrated that the degree of polymerization of inulin, which depends on plant species, harvesting time, extraction and postextraction processes, had a substantial influence on its prebiotic effect. ${ }^{13,14}$ Due to its abundant positive actions toward human health, Jerusalem artichoke tubers, both fresh and cooked ones, have been consumed widely in Thailand as vegetable and food supplement. However, due to a variation in inulin content and a different degree of polymerization in each plant source, an immediate consumption of Jerusalem artichoke tubers may not be sufficient to provide the positive impact on health. Moreover, fresh Jerusalem artichoke tubers are generally unavailable in some geographic areas. This study thus aimed to develop prebiotic granules from Jerusalem artichoke tuber extract, which contains appropriate amount of inulin providing the prebiotic effect. The prebiotic effect of the Jerusalem artichoke tuber extract, indicated by the bacterial growth and acid production was also investigated in the study.

\section{MATERIALS AND METHODS}

Preparation of the Jerusalem artichoke tuber extract

The Jerusalem artichoke extract was prepared according to the method of $\mathrm{Li}$ et al. (2015) with

Cite this article: Rattanakiat S, Pulbutr P, Khunawattanakul W, Sungthong B, Saramunee K. Prebiotic Activity of Polysaccharides Extracted from Jerusalem Artichoke Tuber and Development of Prebiotic Granules. Pharmacogn J. 2020;12(6):1402-11. 
some slight modifications. ${ }^{14}$ The tubers of Jerusalem artichoke (number 2 variety, aged 8-12 weeks) were obtained from the plantation at the Faculty of Agriculture, Khon Kaen University, Khon Kaen, Thailand. The samples were authenticated by the specialist at the groundnut and Jarusalem artichoke research group, the Faculty of Agriculture, Khon Kaen University. Firstly, the samples (500 g) were washed thoroughly with tap water and subsequently chopped into small pieces. The samples were boiled in deionized water for 5 minutes to inactivate inulinase enzyme. The boiled samples were dried at $60^{\circ} \mathrm{C}$ for 24 hours and then ground. The ground samples were boiled in deionized water at $90^{\circ} \mathrm{C}$ for 40 minutes twice and filtered. The filtrate was collected and sufficient amount of $\mathrm{Ca}(\mathrm{OH})_{2}$ was added into the filtrate until reaching the $\mathrm{pH}$ of 11 in order to remove the protein. Subsequently, $\mathrm{H}_{3} \mathrm{PO}_{4}$ was added into the filtrate until the $\mathrm{pH}$ of 8 was obtained to remove the excess $\mathrm{Ca}(\mathrm{OH})_{2}$. The obtained sample was freeze dried at $-40^{\circ} \mathrm{C}$ and kept at $-20^{\circ} \mathrm{C}$ until use. Percent yields of the extract was $52.07 \%$.

\section{Assessment of the prebiotic effect of the JA extract}

Four strains of probiotics, including Lactobacillus acidophilus (TISTR2365), Lactobacillus plantarum (TISTR1465), Bifidobacterium breve (TISTR2130), Bifidobacterium longum (TISTR2195), were used in this study. The probiotic strains were obtained from Thailand Institute of Scientific and Technological Research Institute culture collection, Ministry of Science, and Technology, Thailand. Escherichia coli O157:H7 (DMST12743) was attained from the Department of Medical Sciences Thailand (DMST), Ministry of Public Health, Thailand. The Lactobacillus strains were cultivated anaerobically at $37^{\circ} \mathrm{C}$ in de man Rogosa Sharpe (MRS) broth as described in Li et al., 2015. ${ }^{14}$ The modified MRS broth with the addition of riboflavin $(0.001 \% \mathrm{w} / \mathrm{v})$ and L-cysteine $(0.05 \% \mathrm{w} / \mathrm{v})$ was used as the media for culturing the Bifidobacterium strains. The bacteria were cultured to reach their stationary phase after which they were collected by centrifugation at $2,500 \mathrm{~g}$ at $4^{\circ} \mathrm{C}$ for 15 minutes and washed twice with phosphate-buffered saline (PBS). The cells $(1 \% \mathrm{v} / \mathrm{v})$ was subsequently incubated in the presence of various carbohydrate sources, including the JA extract $(0.5,1$ and $2 \% \mathrm{w} / \mathrm{v})$, the commercial inulin $(0.5,1$ and $2 \% \mathrm{w} / \mathrm{v})$ or glucose $(0.5 \% \mathrm{w} / \mathrm{v})$, which was served as positive control. The broth without carbohydrate source (glucose-free media) was used as negative control. The prebiotic effect of the JA extract was evaluated by monitoring the growth and $\mathrm{pH}$ changes of the incubation media. Growth of the bacteria was monitored every few hours by measuring the optical density (OD) of the cultures at $600 \mathrm{~nm}$. The $\mathrm{pH}$ of the culture media was used as an indicator of acidproducing activity of the bacteria.

Specific growth rate $(\mu)$ was calculated for each microorganism during its exponential growth phase by the equation: $\mu=\left(\ln \mathrm{X}-\ln \mathrm{X}_{0}\right) /\left(\mathrm{t}-\mathrm{t}_{0}\right)$, where $\mathrm{X}$ and $\mathrm{X}_{0}$ were absorbance measured at time $\mathrm{t}$ and $\mathrm{t}_{0}$, respectively. The generation time $(\mathrm{tg})$ was calculated for each culture from the corresponding value of $\mu$ by the equation: $\operatorname{tg}=\ln 2 / \mu .^{15}$

\section{Carbohydrate content assay}

The total carbohydrate content of the JA extract $(0.5 \mathrm{mg} / \mathrm{mL})$ was performed in the 96-well plate using the phenol-sulfuric acid method. ${ }^{16}$ Briefly, in each well, $10 \mu \mathrm{L}$ of the JA extract or glucose (standard), $30 \mu \mathrm{L}$ of water and $40 \mu \mathrm{L}$ of $6.5 \%$ phenol were added. Subsequently, $200 \mu \mathrm{L}$ of $85 \%$ concentrated sulfuric acid $\left(\mathrm{H}_{2} \mathrm{SO}_{4}\right)$ was included and mixed gently but completely with the microplate shaker. The plate was kept at room temperature for 30 minutes and the absorbance was measured at the wavelength of $490 \mathrm{~nm}$ by using absorbance microplate reader (BMG LABTECH, Germany). The total carbohydrate content was calculated from the glucose standard curve.

The reducing sugar assay was performed using the dinitrosalicylic colorimetric method. ${ }^{17} 200 \mu \mathrm{L}$ of the JA extract $(0.5 \mathrm{mg} / \mathrm{mL})$ or glucose (standard) was mixed with $100 \mu \mathrm{L}$ of 3,5-dinitrosalicylic acid (DNS) color reagent $(96 \mathrm{mM}$ DNS and $5.31 \mathrm{M}$ sodium potassium tartrate in $2 \mathrm{M} \mathrm{NaOH}$ ) and then boiled at $85^{\circ} \mathrm{C}$ for 15 minutes. The absorbance of the mixture was measured at the wavelength of $540 \mathrm{~nm}$ by using absorbance microplate reader. The concentration of reducing sugar was calculated from the glucose standard curve. Percent of non-reducing sugar content was calculated by $100-\%$ of reducing sugar content. The experiments were performed in triplicate.

\section{Development of prebiotic granules from the JA extract}

In order to formulate the JA extract granules, the JA extract was mixed with sweetener, erythritol, lactose by geometric dilution method. Then, absolute ethanol was added to the powder until cohesive mass was obtained. The cohesive mass was screened through a mesh-12 sieve and dried at $50^{\circ} \mathrm{C}$ for 24 hours. Dry granule was screened through a mesh16 sieve and the granule was collected in tight container until further studies. General appearance of granule was observed and moisture content of JA extract granule was investigated using moisture balance (Satorious MA30, Scientific Promotion Co., Ltd., Thailand). The 2 g of granule was accurately weighed $\left(\mathrm{W}_{1}\right)$ and heat up to $105{ }^{\circ} \mathrm{C}$ for 30 minutes, then the weight of granule was recorded $\left(\mathrm{W}_{2}\right)$. Moisture content in granules was calculated according to following equation. $\%$ Moisture content $=\left(\mathrm{W}_{1}-\mathrm{W}_{2}\right) \times 100 / \mathrm{W}_{1}$

\section{Statistical analysis}

The data was expressed as mean $\pm \mathrm{SD}$. The statistical analysis was performed by using one-way analysis of variance (ANOVA) followed by the Bonferroni post-hoc test. The difference between data is considered statistically significant when a p-value is less than 0.05 .

\section{RESULTS}

\section{Effects of the JA extract on growth and acid production of probiotics}

The growth-stimulating effect and acid-producing activity of $L$. plantarum, L. acidophilus, B. longum, B. breve were significantly increased in the presence of the JA extract, with the earliest response found in the incubation of $2 \%$ JA extract (Figure 1 and 2). The effects of the $2 \%$ JA extract on growth of L. plantarum, L. acidophilus, B. longum and $B$. breve were significantly higher than those of glucose (positive control) at certain incubation periods. Meanwhile, the acid productions of $L$. plantarum, $L$. acidophilus and B. longum in the presence of the $2 \%$ JA extract were higher than that in the presence of glucose at some points of incubation.

The JA extracts produced a significant increase in specific growth rate and a substantial decrease in generation time of $L$. plantarum and L. acidophilus (Table 1). However, neither the JA extract nor the commercial inulin at any concentration tested affect on the specific growth rate and generation time of $B$. longum and B. breve.

The JA extract significantly increased the growth of $E$. coli and its acid production with the most pronounced action found with the highest concentration used (Figure 3). The JA extract, the commercial inulin as well as glucose did not cause any change in specific growth rate and generation time of $E$. coli (Table 1).

\section{Carbohydrate content assay}

From, the total carbohydrate assay, the whole content of the JA extract was found as carbohydrate with the \% total carbohydrate of $111.29 \pm$ $46.69(\mathrm{n}=3)$. The JA extract contained a significantly high proportion of non-reducing sugar of $75.43 \pm 0.91 \%(n=3)$, whilst its reducing sugar content was $24.57 \pm 0.91 \%$. 
Lactobacillus plantarum

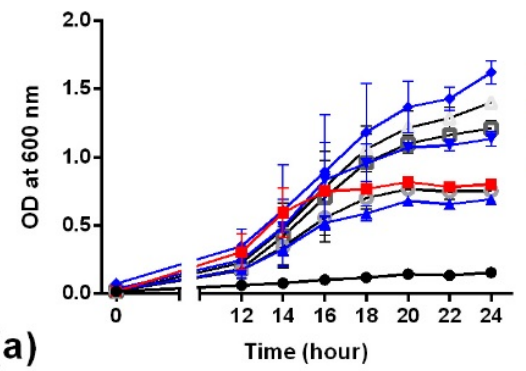

${ }^{a} \mathrm{p}<0.05$ when compared with negative control (MRS without glucose) at $\mathrm{t}=12,16,18,20,22$ and $24 \mathrm{hr}$

${ }^{b} \mathrm{p}<0.05$ when compared with negative control (MRS without glucose) at $\mathrm{t}=16,18,20,22$ and $24 \mathrm{hr}$

${ }^{c} \mathrm{p}<0.05$ when compared with negative control (MRS without glucose) at $\mathrm{t}=18,20,22$ and $24 \mathrm{hr}$

${ }^{d} p<0.05$ when compared with positive control (MRS with glucose) at $t$ $=20,22$ and $24 \mathrm{hr}$

${ }^{e} \mathrm{p}<0.05$ when compared with positive control (MRS with glucose) at $\mathrm{t}$ $=22$ and $24 \mathrm{hr}$ $\rightarrow$ MRS without glucose

- MRS with glucose $c$

$\rightarrow$ JA extract $0.5 \% \mathrm{c}$

A extract $1 \%$ b,e

-थ- Inulin $0.5 \% \mathrm{c}$

$\rightarrow-$ Inulin $1 \% c, d$

-- Inulin $2 \% c, d$

(b)

Lactobacillus acidophilus

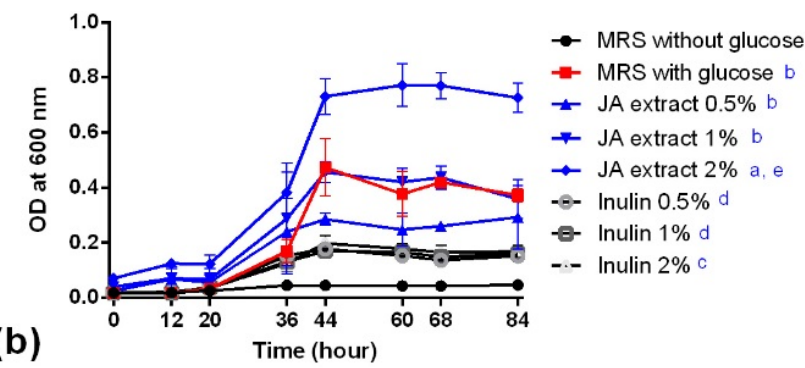

${ }^{a} \mathrm{p}<0.05$ when compared with negative control (MRS without glucose) at $\mathrm{t}=12,20,36,44,60,68$ and 84

${ }^{b} \mathrm{p}<0.05$ when compared with negative control (MRS without glucose) at $\mathrm{t}=44,60,68$ and $84 \mathrm{hr}$

${ }^{c} p<0.05$ when compared with negative control (MRS without glucose) at $\mathrm{t}=44$ and $68 \mathrm{hr}$

${ }^{d} p<0.05$ when compared with negative control (MRS without glucose) at $\mathrm{t}=68 \mathrm{hr}$

${ }^{e} \mathrm{p}<0.05$ when compared with positive control (MRS with glucose) at $t$ $=20,44,60,68,84 \mathrm{hr}$
Lactobacillus plantarum

I

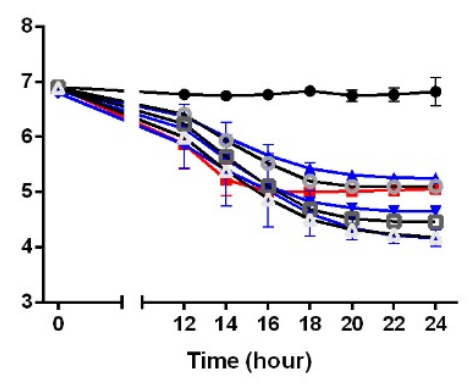

${ }^{a} \mathrm{p}<0.05$ when compared with negative control (MRS without glucose) at $\mathrm{t}=14,16,18,20,22$ and $24 \mathrm{hr}$

${ }^{b} p<0.05$ when compared with negative control (MRS without glucose) at $\mathrm{t}=16,18,20,22$ and $24 \mathrm{hr}$

${ }^{c} \mathrm{p}<0.05$ when compared with positive control (MRS with glucose) at $t$ $=20,22$ and $24 \mathrm{hr}$

${ }^{d} p<0.05$ when compared with positive control (MRS with glucose) at $t$ $=20$ and $22 \mathrm{hr}$

- JA extract $0.5 \% b, d$

$\rightarrow \mathrm{JA}$ extract $1 \% \mathrm{~b}, \mathrm{c}$

JA extract $2 \%$

$\rightarrow$ Inulin $1 \%$ b,c

- Inulin $2 \%$ a,c
- MRS without glucose

$\rightarrow$ MRS with glucose a

\section{(c)}

\footnotetext{
.
}

Figure 1: Growth kinetics of (a) Lactobacillus plantarum and (b) Lactobacillus acidophilus and pH changes of media inoculated with (c) L. plantarum and (d) L. acidophilus in MRS media supplemented with glucose $(0.5 \% \mathrm{w} / \mathrm{v}), \mathrm{JA}$ extract $(0.5 \%, 1 \%, 2 \% \mathrm{w} / \mathrm{v})$ and inulin $(0.5 \%, 1 \%, 2 \% \mathrm{w} / \mathrm{v})$ during $24 \mathrm{and} 84 \mathrm{hr}$ incubations for $L$. plantarum and L. acidophilus, respectively $(n=3)$ 

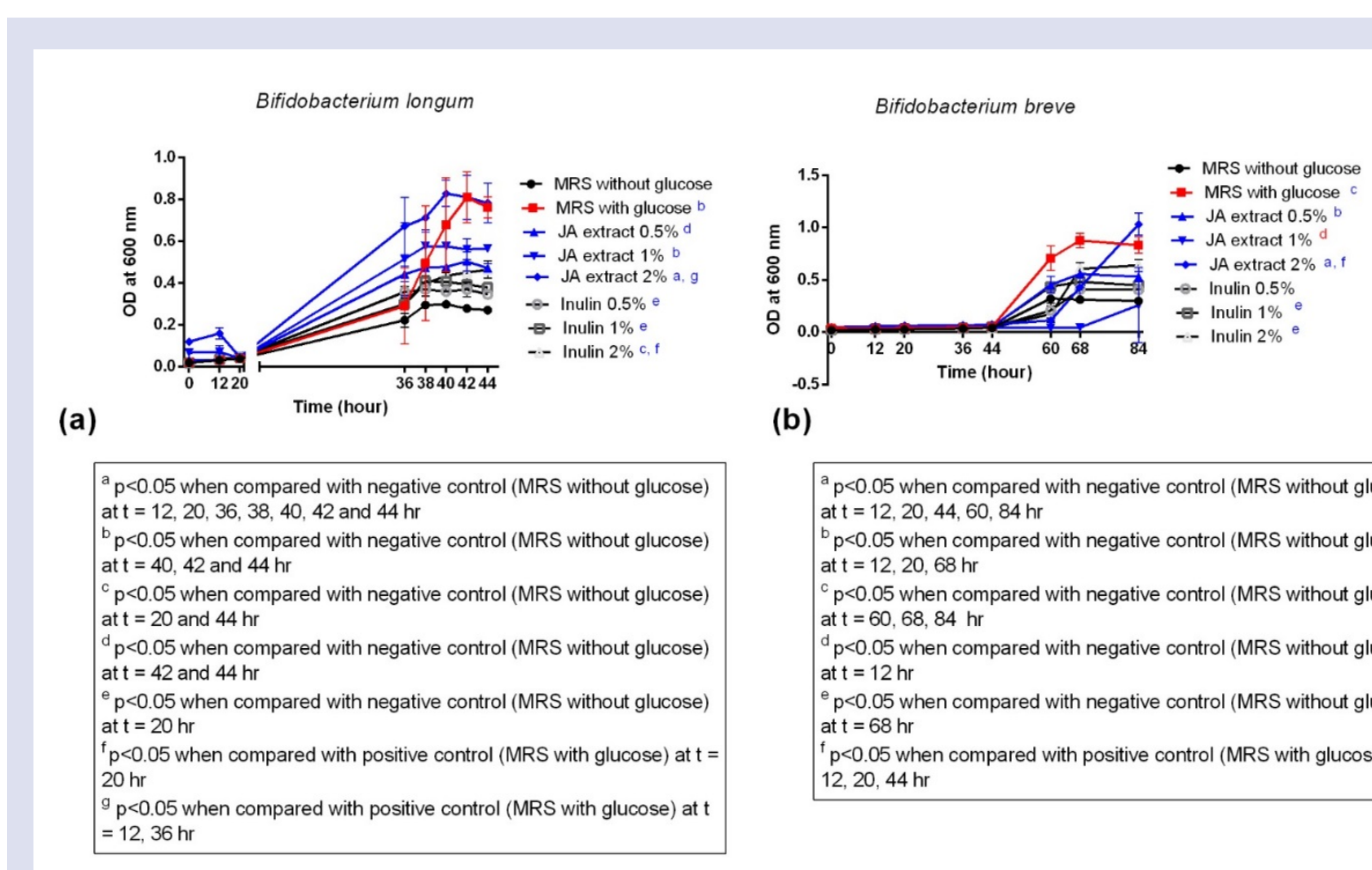

(b)

${ }^{a} p<0.05$ when compared with negative control (MRS without glucose)
at $t=12,20,44,60,84 \mathrm{hr}$
${ }^{b} p<0.05$ when compared with negative control (MRS without glucose)
at $t=12,20,68 \mathrm{hr}$
${ }^{c} p<0.05$ when compared with negative control (MRS without glucose)
at $t=60,68,84 \mathrm{hr}$
${ }^{d} p<0.05$ when compared with negative control (MRS without glucose)
at $t=12 \mathrm{hr}$
${ }^{e} p<0.05$ when compared with negative control (MRS without glucose)
at $t=68 \mathrm{hr}$
${ }^{f} p<0.05$ when compared with positive control (MRS with glucose) at $t=$
$12,20,44 \mathrm{hr}$
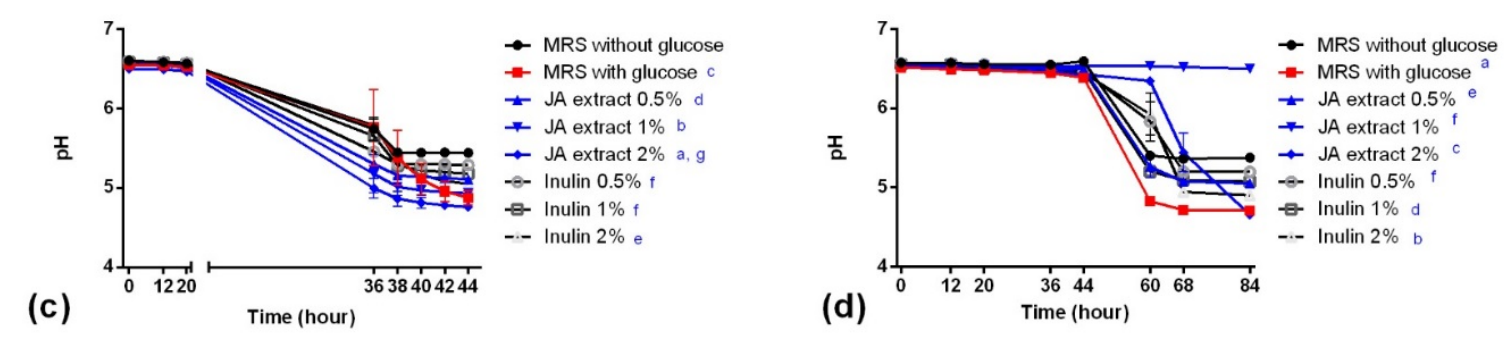
${ }^{a} \mathrm{p}<0.05$ when compared with negative control (MRS without glucose) at $\mathrm{t}=12,20,36,38,40,42,44 \mathrm{hr}$
${ }^{\mathrm{b}} \mathrm{p}<0.05$ when compared with negative control (MRS without glucose) at $\mathrm{t}=12,20,38,40,42,44 \mathrm{hr}$
${ }^{c} \mathrm{p}<0.05$ when compared with negative control (MRS without glucose) at $\mathrm{t}=12,20,40,42,44 \mathrm{hr}$
${ }^{d} p<0.05$ when compared with negative control (MRS without glucose) at $\mathrm{t}=20,40,42,44 \mathrm{hr}$
${ }^{e} p<0.05$ when compared with negative control (MRS without glucose) at $\mathrm{t}=40,42,44 \mathrm{hr}$
${ }^{f} p<0.05$ when compared with negative control (MRS without glucose) at $t$ $=42,44 \mathrm{hr}$
${ }^{\mathrm{g}} \mathrm{p}<0.05$ when compared with positive control (MRS with glucose) at $\mathrm{t}=$ $12,20,36,38,40,42,44 \mathrm{hr}$

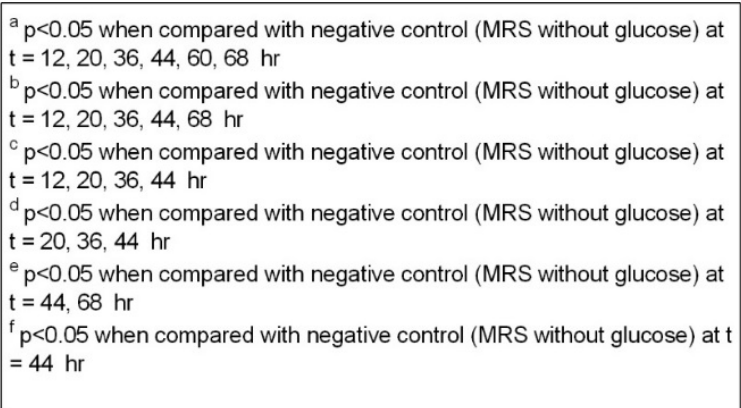

Figure 2: Growth kinetics of (a) Bifidobacterium longum and (b) Bifidobacterium breve and $\mathrm{pH}$ changes of media inoculated with (c) B. longum and (d) B. breve in MRS media supplemented with glucose $(0.5 \% \mathrm{w} / \mathrm{v})$, JA extract $(0.5 \%, 1 \%, 2 \% \mathrm{w} / \mathrm{v})$ and inulin $(0.5 \%, 1 \%, 2 \% \mathrm{w} / \mathrm{v})$ during 44 and $84 \mathrm{hr}$ incubations for $B$. longum and $B$. breve, respectively $(\mathrm{n}=3)$. 


\section{Escherichia coli}

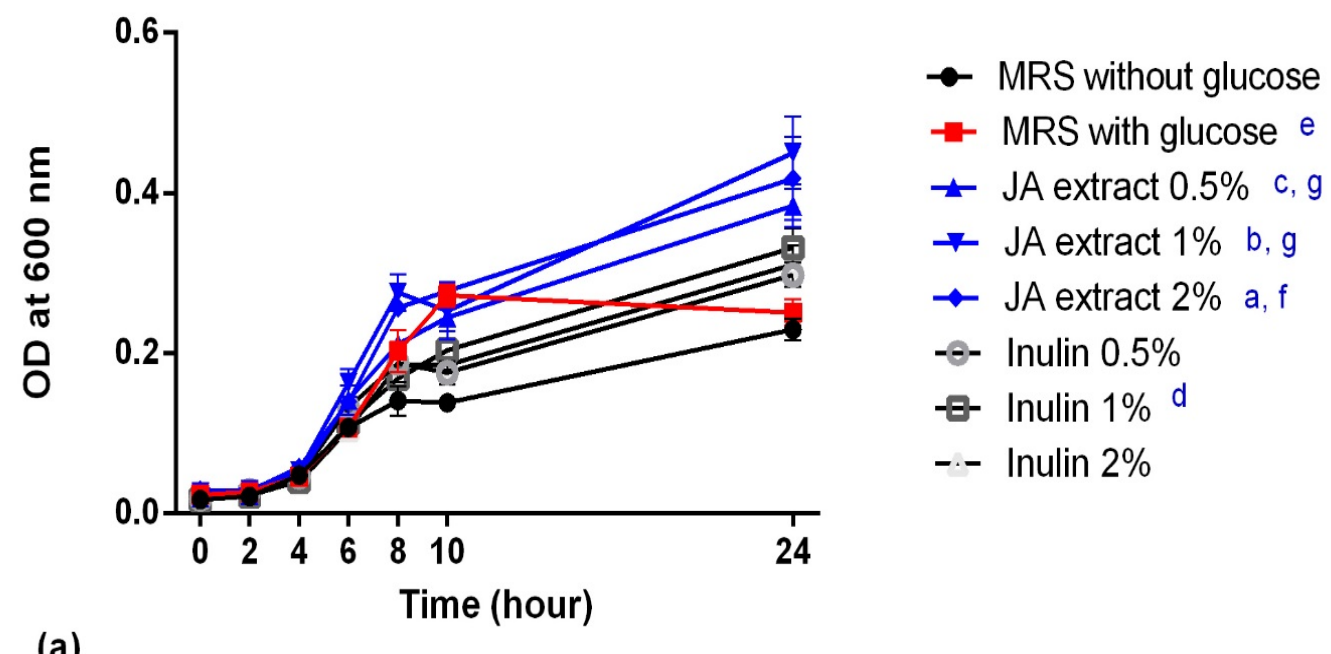

(a)

${ }^{a} p<0.05$ when compared with negative control (MRS without glucose) at $t=4,6,8,10,24 \mathrm{hr}$

${ }^{b} p<0.05$ when compared with negative control (MRS without glucose) at $t=6,8,10,24 \mathrm{hr}$

${ }^{c} p<0.05$ when compared with negative control (MRS without glucose) at $t=6,10,24 \mathrm{hr}$

${ }^{d} p<0.05$ when compared with negative control (MRS without glucose) at $t=10,24 \mathrm{hr}$

${ }^{e} p<0.05$ when compared with negative control (MRS without glucose) at $t=10 \mathrm{hr}$

${ }^{f} p<0.05$ when compared with positive control (MRS with glucose) at $t=4,6,24 \mathrm{hr}$

${ }^{g} \mathrm{p}<0.05$ when compared with positive control (MRS with glucose) at $\mathrm{t}=6,24 \mathrm{hr}$

\section{Escherichia coli}

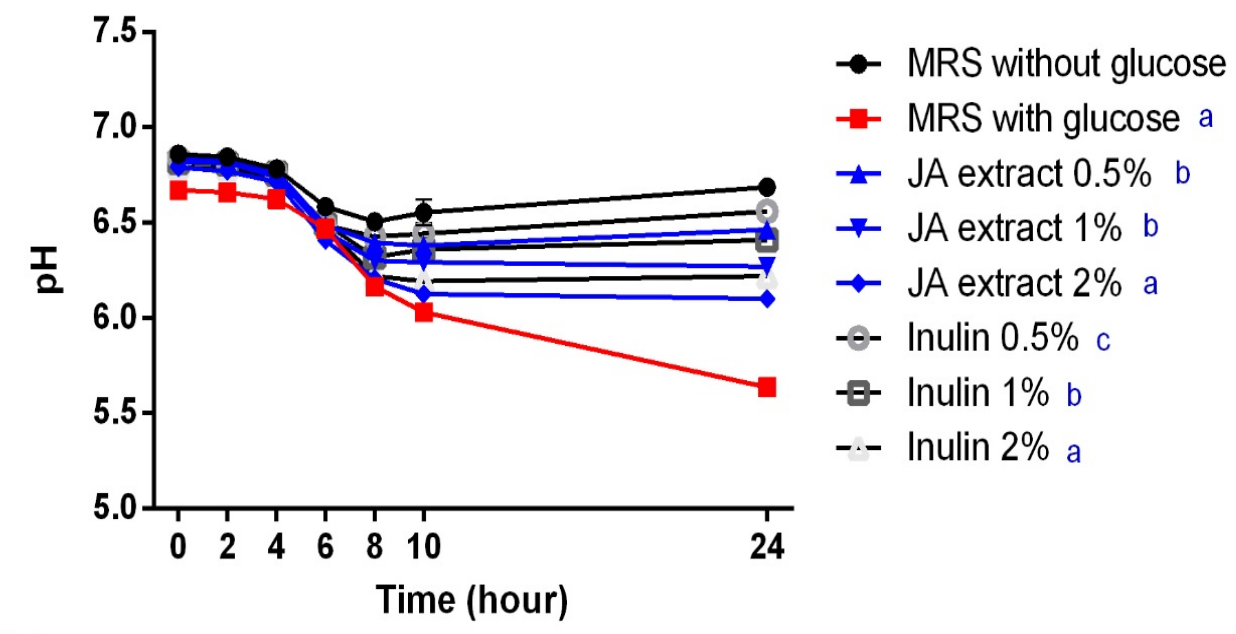

(b)

\footnotetext{
${ }^{a} p<0.05$ when compared with negative control (MRS without glucose) at $t=2,4,6,8,10,24 \mathrm{hr}$

${ }^{b} p<0.05$ when compared with negative control (MRS without glucose) at $t=6,8,10,24 \mathrm{hr}$

${ }^{c} p<0.05$ when compared with negative control (MRS without glucose) at $t=6,8,24 \mathrm{hr}$
} 
Table 1: Specific growth rate $(\mu)$ and generation time $(t g)$ of microorganisms during its exponential growth phase $(m e a n \pm$ SD, $n=3)$.

\begin{tabular}{|c|c|c|c|c|c|c|c|c|c|c|}
\hline \multirow[t]{2}{*}{ Treatment } & \multicolumn{2}{|c|}{$\begin{array}{l}\text { L. plantarum } \\
\text { (t=16 hr) }\end{array}$} & \multicolumn{2}{|c|}{$\begin{array}{l}\text { L. acidophilus } \\
\qquad(\mathrm{t}=44 \mathrm{hr})\end{array}$} & \multicolumn{2}{|c|}{$\begin{array}{l}\text { B. longum } \\
(\mathrm{t}=40 \mathrm{hr})\end{array}$} & \multicolumn{2}{|c|}{$\begin{array}{l}\text { B. breve } \\
(t=60 \mathrm{hr})\end{array}$} & \multicolumn{2}{|c|}{$\begin{array}{c}\text { E.coli } \\
(t=6 \mathrm{hr})\end{array}$} \\
\hline & $\mu$ & $\operatorname{tg}$ & $\mu$ & $\operatorname{tg}$ & $\mu$ & $\operatorname{tg}$ & $\mu$ & $\operatorname{tg}$ & $\mu$ & $\operatorname{tg}$ \\
\hline $\begin{array}{l}\text { MRS no } \\
\text { glucose }\end{array}$ & $0.1127 \pm 0.0120$ & $\begin{array}{c}6.1994 \pm \\
0.6947\end{array}$ & $\begin{array}{c}0.0320 \pm \\
0.0005\end{array}$ & $\begin{array}{c}21.6432 \pm \\
0.3735\end{array}$ & $\begin{array}{c}0.0696 \pm \\
0.0006\end{array}$ & $\begin{array}{c}9.9560 \pm \\
0.0930\end{array}$ & $\begin{array}{c}0.0450 \pm \\
0.0007\end{array}$ & $\begin{array}{c}15.4048 \pm \\
0.2409\end{array}$ & $\begin{array}{c}0.4415 \pm \\
0.2240\end{array}$ & $\begin{array}{c}1.8114 \pm \\
0.7154\end{array}$ \\
\hline $\begin{array}{l}\text { MRS with } \\
\text { glucose }\end{array}$ & $0.2327 \pm 0.0120^{*}$ & $\begin{array}{c}2.9839 \pm \\
0.1574^{*}\end{array}$ & $\begin{array}{c}0.0341 \pm \\
0.0007^{\star}\end{array}$ & $\begin{array}{c}20.3399 \pm \\
0.4466\end{array}$ & $\begin{array}{c}0.0877 \pm \\
0.0067^{\star}\end{array}$ & $\begin{array}{c}7.9282 \pm \\
0.5908^{\star}\end{array}$ & $\begin{array}{c}0.0475 \pm \\
0.0070\end{array}$ & $\begin{array}{c}14.8079 \pm \\
2.2258\end{array}$ & $\begin{array}{c}0.3869 \pm \\
0.2245\end{array}$ & $\begin{array}{c}2.1533 \pm \\
0.9362\end{array}$ \\
\hline $\begin{array}{c}\text { JA extract } \\
0.5 \%\end{array}$ & $0.1799 \pm 0.0090$ & $\begin{array}{c}3.8595 \pm \\
0.1959^{*}\end{array}$ & $\begin{array}{c}0.0540 \pm \\
0.0024^{*}\end{array}$ & $\begin{array}{c}12.8502 \pm \\
0.5762^{*}\end{array}$ & $\begin{array}{c}0.0697 \pm \\
0.0017\end{array}$ & $\begin{array}{c}9.9412 \pm \\
0.2439\end{array}$ & $\begin{array}{c}0.0397 \pm \\
0.0016\end{array}$ & $\begin{array}{c}17.4972 \pm \\
0.7381\end{array}$ & $\begin{array}{c}0.4451 \pm \\
0.2118\end{array}$ & $\begin{array}{c}1.7703 \pm \\
0.6753\end{array}$ \\
\hline JA extract $1 \%$ & $0.1922 \pm 0.0275^{\star}$ & $\begin{array}{c}3.6569 \pm \\
0.5321^{\star}\end{array}$ & $\begin{array}{c}0.0552 \pm \\
0.0040^{\star}\end{array}$ & $\begin{array}{c}12.6000 \pm \\
0.9288^{\star}\end{array}$ & $\begin{array}{c}0.0572 \pm \\
0.0076\end{array}$ & $\begin{array}{c}12.2444 \pm \\
1.5387\end{array}$ & $\begin{array}{c}0.0042 \pm \\
0.0009\end{array}$ & $\begin{array}{c}169.7798 \pm \\
38.2338\end{array}$ & $\begin{array}{c}0.4225 \pm \\
0.1858\end{array}$ & $\begin{array}{c}1.8318 \pm \\
0.6551\end{array}$ \\
\hline JA extract $2 \%$ & $0.1506 \pm 0.0252$ & $\begin{array}{c}4.6935 \pm \\
0.8129\end{array}$ & $\begin{array}{c}0.0531 \pm \\
0.0030^{*}\end{array}$ & $\begin{array}{c}13.0846 \pm \\
0.7329^{\star}\end{array}$ & $\begin{array}{c}0.0511 \pm \\
0.0026\end{array}$ & $\begin{array}{c}13.5924 \pm \\
0.6887\end{array}$ & $\begin{array}{c}0.0140 \pm \\
0.0044\end{array}$ & $\begin{array}{c}53.4038 \pm \\
19.0857\end{array}$ & $\begin{array}{c}0.3767 \pm \\
0.2054\end{array}$ & $\begin{array}{c}2.1663 \pm \\
0.8984\end{array}$ \\
\hline Inulin $0.5 \%$ & $0.2085 \pm 0.02923^{*}$ & $\begin{array}{c}3.3731 \pm \\
0.5144^{*}\end{array}$ & $\begin{array}{c}0.0505 \pm \\
0.0032^{\star}\end{array}$ & $\begin{array}{c}13.7529 \pm \\
0.8881^{\star}\end{array}$ & $\begin{array}{c}0.0715 \pm \\
0.0001\end{array}$ & $\begin{array}{c}9.6933 \pm \\
0.0122\end{array}$ & $\begin{array}{c}0.0364 \pm \\
0.0058\end{array}$ & $\begin{array}{c}19.3359 \pm \\
3.0526\end{array}$ & $\begin{array}{c}0.4551 \pm \\
0.2046\end{array}$ & $\begin{array}{c}1.7055 \pm \\
0.6093\end{array}$ \\
\hline Inulin $1 \%$ & $0.2255 \pm 0.02967^{\star}$ & $\begin{array}{c}3.1134 \pm \\
0.4434^{*}\end{array}$ & $\begin{array}{c}0.0491 \pm \\
0.0056^{*}\end{array}$ & $\begin{array}{c}14.1982 \pm \\
1.6318^{\star}\end{array}$ & $\begin{array}{c}0.07570 \pm \\
0.0015\end{array}$ & $\begin{array}{c}9.1583 \pm \\
0.1779\end{array}$ & $\begin{array}{c}0.0490 \pm \\
0.0022\end{array}$ & $\begin{array}{c}14.1686 \pm \\
0.6264\end{array}$ & $\begin{array}{c}0.4391 \pm \\
0.2263\end{array}$ & $\begin{array}{c}1.8288 \pm \\
0.7291\end{array}$ \\
\hline Inulin $2 \%$ & $0.2328 \pm 0.0299^{*}$ & $\begin{array}{l}3.0121 \pm \\
0.4126^{\star}\end{array}$ & $\begin{array}{l}0.0527 \pm \\
0.0024^{\star}\end{array}$ & $\begin{array}{c}13.1787 \pm \\
0.6173^{\star}\end{array}$ & $\begin{array}{c}0.0756 \pm \\
0.0010\end{array}$ & $\begin{array}{c}9.1675 \pm \\
0.1176\end{array}$ & $\begin{array}{c}0.0329 \pm \\
0.0065\end{array}$ & $\begin{array}{c}21.6112 \pm \\
3.9970\end{array}$ & $\begin{array}{c}0.4098 \pm \\
0.2222\end{array}$ & $\begin{array}{c}1.9906 \pm \\
0.8300\end{array}$ \\
\hline
\end{tabular}

${ }^{*} p<0.05$ when compared with negative control (MRS without glucose)

Table 2: The formulation of the developed JA extract granules.

\begin{tabular}{cc}
\hline Ingredients & $\%(\mathrm{w} / \mathrm{w})$ \\
\hline JA extract & 9.51 \\
Sweetener & 0.14 \\
Erythritol & 42.80 \\
Absolute ethanol & $\mathrm{qs}$ \\
Lactose qs to & 47.55 \\
\hline
\end{tabular}

\section{Development of prebiotic granules from JA extract}

The formulation of JA extract granules is demonstrated in Table 2. The obtained granule was brown and asymmetric in shape. The granule was freely flowed. The 10.515 grams of granule (contained $1 \mathrm{~g}$ of JA extract) could be dissolved in $150 \mathrm{~mL}$ of distilled water and produced brown and clear solution with slightly sweet taste. The moisture content of granules was $4.00 \pm 0.20 \%$.

\section{DISCUSSION}

The JA extract at the highest concentration tested (2\%) caused a significant increase in the growth of every probiotics tested, including L. plantarum L. acidophilus B. longum and B. breve. The growth promoting effects of the $2 \%$ JA extract were detected as early as 12 hourincubation, and this action was maintained throughout the observed incubation period. The growth of probiotics in the presence of the $2 \%$ JA extract were significantly higher than that in the presence of glucose at particular incubation period. Additionally, for every probiotic tested, the growth stimulating effects of the JA extract were detected earlier than that of the commercial inulin at the same concentration used. Probiotics including certain species of lactobacillus and bifidobacteria can metabolize carbohydrate into short chain fatty acids, which result in a lower $\mathrm{pH}$ of the culture media. The $\mathrm{pH}$ drop of culture media thus can be used as an indicator of bacterial fermentability. ${ }^{18}$ In this study, the changes of $\mathrm{pH}$ in the incubation media were consistent with the bacterial growth indicated by the optical density absorbance. The JA extracts and the commercial inulin performed their prebiotic effects in a concentration-dependent manner. The JA extract and commercial inulin at the lower concentrations tested (0.5 and $1 \%$ ) had a lesser growth-promoting and acid-producing activities.

In addition to the changes in optical density and $\mathrm{pH}$, the specific growth rate and generation time of the lactobacilli were significantly increased and decreased, respectively in the JA extract and the commercial inulin incubations of the lactobacilli. Nonetheless, these growth kinetic parameters of the bifidobacteria species did not change significantly in the presence of either the JA extract or the commercial inulin. These two terms indicate how rapid the bacteria grow during its exponential growth phase. Thus, the JA extract and the commercial inulin did not cause a significant change in the rate of bifidobacterium multiplication during the exponential phase where the bacterial growth rate is the most rapid. Thus, lactobacilli were likely to have a higher capability than bifidobacteria regarding to the utilization of the JA extract and the commercial inulin as energy sources. It has been reported that different species of lactobacilli and bifidobacteria selectively utilized different sources of carbohydrate. ${ }^{19}$ The interspecies differences between lactobacilli and bifidobacteria with regard to their carbohydrate type utilization were also indicated in their study. Inulin and polydextrose appeared to be relatively poor carbohydrate substrates for bifidobacterial growth. ${ }^{19}$

The degree of polymerization of fructans has been indicated as an important factor for the utilization of fructans by probiotics. ${ }^{3}$ It has been indicated that inulin with low degree of polymerization has the higher prebiotic activities. ${ }^{14}$ Several studies showed that the degree of polymerization of fructans from Jerusalem artichoke tubers were relatively low when compared with that of commercial inulin. ${ }^{20-22}$ This is consistency with our results where the JA extract had a more pronounced action on the bacterial growth than the commercial inulin. The degree of polymerization of fructans from Jerusalem artichoke has been described to depend on not only the cultivation factors of the plant, such as the variety, climate conditions and time of harvest, but also the host factors, including $\mathrm{pH}$ of the gastrointestinal tract. ${ }^{15,20-22}$ Additionally, other factors affecting the fermentability of the prebiotics include water solubility, chemical structure, chain length, branched or linear structure and composition of monomer units. ${ }^{3}$ Our 
results showed that the prebiotics effect of the JA extract also depends on the types of probiotics. Lactobacilli were likely to be more responsive than bifidobacteria to the prebiotic effect of the JA extract.

In this study, the JA extract and the commercial inulin had a stimulating action on E. coli growth and acid production. However, the specific growth rate and generation time were not changed significantly. This is in agreement with the results of Elaheh et al. (2016), where the growth stimulating actions of the JA extract and inulin were also demonstrated..$^{15}$ It should be noted that the growth of E. coli in the presence of the JA extract was significantly higher than that in the presence of glucose at 24 hour-incubation. This is consistency with the results of López-Molina et al. (2005), which showed the longer lasting growth-stimulating action of artichoke inulin on E. coli. ${ }^{23}$ The ability of $E$. coli to use fructooligosaccharides as a carbon source is still ambiguous. The stimulatory action of fructooligosaccharides on growth of E. coli has been reported in some studies. ${ }^{24,25}$ On the other hand, the null action of fructooligosaccharides on growth of $E$. coli was also documented. ${ }^{26,27}$ Fooks and Gibson (2012) showed that the probiotics could inhibit the growth of pathogenic bacteria including E. coli strongly when the bacteria were co-cultured. Thus, the growth stimulating effect of the JA extract on E. coli sole culture found here did not literally implied the lack of prebiotic properties of the extract. ${ }^{28}$

The JA extract was hygroscopic since inulin and other polysaccharides possess hygroscopic property. ${ }^{29}$ Lactose was therefore selected as an adsorbent and diluent in the developed formulation of the JA extract granules. The JA extract: lactose at ratio of 1:5 was sufficient to adsorb the moisture and maintain the dryness of the developed granules. These indicated a possibility of the JA extract to formulate as an instant granules. Nevertheless, other study on the properties of the developed granules such as a stability test should also be performed. Further studies are still required to investigate the in vivo prebiotics action of the developed inulin granule formulation to optimize the appropriate JA extract dose.

\section{CONCLUSIONS}

The JA extract at the highest concentration tested (2\%) caused a significant increase in the growth and acid production of every probiotics tested, including $L$. plantarum, L. acidophilus, B. longum and $B$. breve. The granules containing the JA extract possessing the prebiotic property were formulated in our study. The developed granule was well dissolved in water and resulted in a brown and clear solution with slightly sweet taste. Nonetheless, further experiments on the in vivo prebiotic effect of the developed preparation should be additionally investigated.

\section{ACKNOWLEDGEMENTS}

This project was financially supported by Mahasarakham University research grant fiscal year 2018 .

\section{REFERENCES}

1. Roberfroid MB. Concepts in functional foods: the case of inulin and oligofructose. J. Nutr. 1999;129(7 Suppl):1398S-401S

2. Roberfroid M. Prebiotics: the concept revisited. J. Nutr. 2007;137(3 Suppl 2):830S-7S.

3. Biedrzycka E, Bielecka M. Prebiotic effectiveness of fructans of different degrees of polymerization. Trends Food Sci Technol. 2004;15:170-5.

4. Ramnani P, Gaudier E, Bingham M, van Bruggen P, Tuohy KM, Gibson GR. Prebiotic effect of fruit and vegetable shots containing Jerusalem artichoke inulin: A human intervention study. Br J Nutr. 2010;104(2):233-40.
5. Bosscher D, Van Loo J, Franck A. Inulin and oligofructose as prebiotics in the prevention of intestinal infections and diseases. Nutr Res Rev. 2006;19:216-26.

6. Bosscher D, Breynaert A, Pieters L, Hermans N. Food-based strategies to modulate the composition of the intestinal microbiota and their associated health effects. J Physiol Pharmacol. 2009;Suppl6:5-11.

7. Fukuda S, Toh H, Hase K, Oshima K, Nakanishi Y, Yoshimura K, et al Bifidobacteria can protect from enteropathogenic infection through production of acetate. Nature. 2011;469:543-7.

8. Causey JL, Feirtag JM, Gallaher DD, Tungland BC, Slavin JL. Effects of dietary inulin on serum lipids, blood glucose and the gastrointestinal environment in hypercholesterolemic men. Nutr. Res. 2000;20:191-201.

9. Brighenti F. Dietary fructans and serum triacylglycerols: a meta-analysis of randomized controlled trials. J Nutr. 2007;11:S2552-6.

10. Guess ND, Dornhorst A, Oliver N, Bell JD, Thomas EL, Frost GS. A randomized controlled trial: the effect of inulin on weight management and ectopic fat in subjects with prediabetes. Nutr Metab (Lond). 2015;12:36.

11. Saengthongpinit $W$. Influence of harvest time and storage temperature on characteristics of inulin from Jerusalem artichoke and physicochemical properties of inulin-starch mixed gel. Ph.D Thesis, Kasetsart University, Bangkok, Thailand, 2005.

12. Kays SJ, Nottingham SF. Biology and chemistry of Jerusalem artichoke (Helianthus tuberosus L.). Boca Raton: CRC Press; 2008.

13. Li D, Kim JM, Jin Z, Zhou J. Prebiotic effectiveness of inulin extracted from edible burdock. Anaerobe. 2008;14(1):29-34

14. Li W, Zhang J, Yu C, Li Q, Dong F, Wang G, et al. Extraction, degree of polymerization determination and prebiotic effect evaluation of inulin from Jerusalem artichoke. Carbohydr Polym. 2015;121:315-9.

15. Elaheh M, Ali MS, Elnaz M, Ladan N. Prebiotic effect of Jerusalem artichoke (Helianthus tuberosus) fructans on the growth performance of Bifidobacterium bifidum and Escherichia coli. Asian Pac J Trop Dis. 2016;6(5):385-9.

16. Rasouli M, Ostovar-Ravari A, Shokri-AfraEur H. Characterization and improvement of phenol-sulfuric acid microassay for glucose-based glycogen. Rev Med Pharmacol Sci. 2014;18(14):2020-4

17. Ali H, Houghton PJ, Soumyanath A. $\alpha$-Amylase inhibitory activity of some Malaysian plants used to treat diabetes; with particular reference to Phyllanthus amarus. J. Ethnopharmacol. 2006;107(3):449-55

18. Winarti S, Harmayani E, Marsono $Y$, Pranoto $Y$. Effect of inulin isolated from lesser yam (Dioscoreaesculenta) on the growth of probiotics bacteria and SCFA formation during fermentation. Int Res J Microbiol. 2013;4(2):53-63.

19. Watson D, O'Connell Motherway M, Schoterman MH, van Neerven RJ Nauta A, van Sinderen D. Selective carbohydrate utilization by lactobacilli and bifidobacteria. J Appl Microbiol. 2012;114(4):1132-46.

20. Böhm A, Kaiser I, Trebstein A, Henle T. Heat-induced degradation of inulin. Eur Food Res Technol. 2005;220:466-71.

21. Bekers M, Grube M, Upite D, Kaminiska E, Linde R, Scherbaka R, et al. Carbohydrate in Jerusalem artichoke powder suspension. Nutr Food Sci. 2007:37(1):42-9.

22. PaseepholT, Small D, Sherkat F. Process optimisation for fractionating Jerusalem artichoke fructans with ethanol using response surface methodology. Food Chem. 2007;104:73-80

23. López-Molina D, Navarro-Martínez MD, Rojas Melgarejo F, Hiner AN, Chazarra S Rodríguez-López JN. Molecular properties and prebiotic effect of inulin obtained from artichoke (Cynara scolymus L.). Phytochemistry. 2005;66(12):1476-84.

24. Roberfroid M. Inulin-type fructans: functional food ingredients. Boca Raton: CRC Press; 2004.

25. Vijayakumari SJ, Sasidharannair NK, Nambisan B, Mohandas C. Optimization of media and temperature for enhanced antimicrobial production by bacteria associated with Rhabditis sp. Iran J Microbiol. 2013;5(2):136-41.

26. Van Laere KM, Hartemink R, Bosveld M, Schols HA, Voragen AG. Fermentation of plant cell wall derived polysaccharides and their corresponding oligosaccharides by intestinal bacteria. J Agric Food Chem. 2000;48:1644-52.

27. Holt SM, Miller-Fosmore CM, Côté GL. Growth of various intestinal bacteria on alternansucrase-derived oligosaccharides. Lett Appl Microbiol. 2005;40(5):38590.

28. Fooks LJ, Gibson GR. In vitro investigations of the effect of probiotics and prebiotics on selected human intestinal pathogens. FEMS Microbiol Ecol. 2002;39:67-75

29. Pourfarzad A, Ahmadian Z, Habibi-Najafi MB. Interactions between polyols and wheat biopolymers in a bread model system fortified with inulin: A Fourier transform infrared study. Heliyon. 2018;4:e01017. 


\section{GRAPHICAL ABSTRACT}

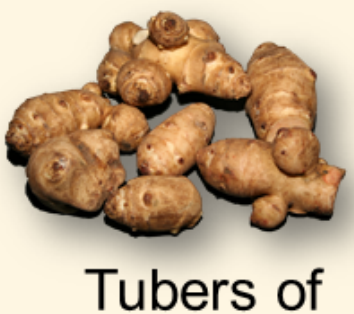

\section{Crude polysaccharide extract of Jerusalem artichoke}

Tubers of Jerusalem artichoke (Helianthus tuberosus L.)

\section{Granule formulation}

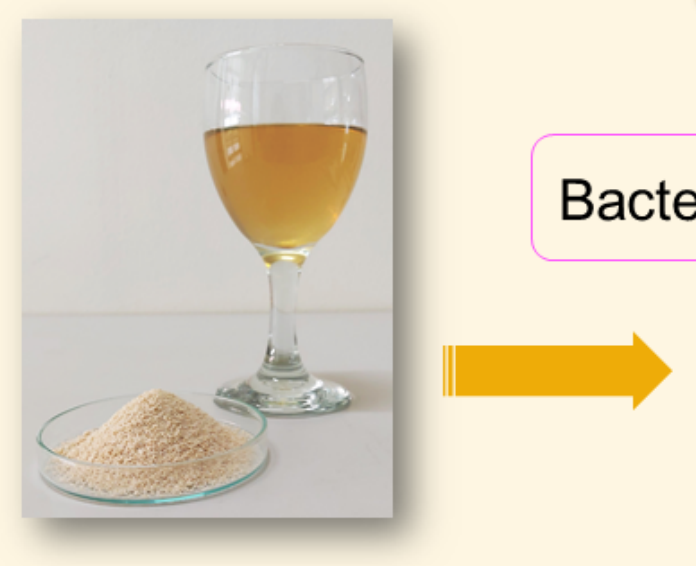

Prebiotic effect

\section{Probiotics}

L. plantarum, L. acidophilus, $B$. longum and $B$. breve

\section{Prebiotic food product}

\section{ABOUT AUTHORS}

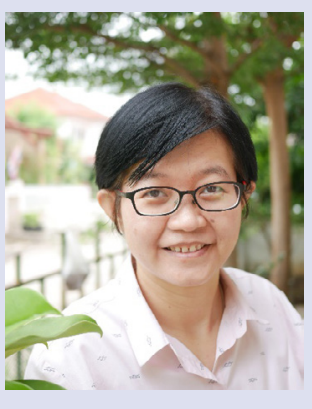

Name: Sakulrat Rattanakiat, Ph.D.

Contact: Faculty of Pharmacy, Mahasarakham University, Maha Sarakham, Thailand 44150

E-mail: sakulrat.r@msu.ac.th

Mobile Phone: (66)-86-771-8949

Current Position: Assistant Professor, Faculty of Pharmacy, Mahasarakham University, Thailand

Area of interest: Microbiology, Biological activity of medicinal plants and natural products Education:

2009: Ph.D. (Pharmaceutical Sciences), Graduate School of Pharmaceutical Sciences, Kyoto University, Japan

2002: M.Sc. in Pharm (Microbiology), Faculty of Pharmaceutical Sciences, Chulalongkorn University, Thailand

2000: B.Sc. in Pharm (1 $1^{\text {st }}$ Honorary), Faculty of Pharmaceutical Sciences, Chulalongkorn University, Thailand 


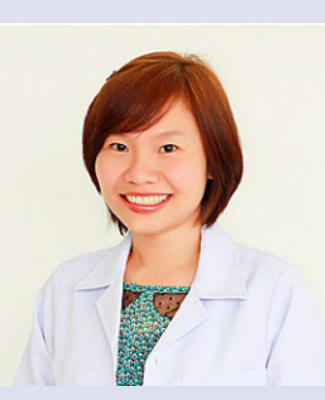

\section{Name: Pawitra Pulbutr, Ph.D.}

Contact: Faculty of Pharmacy, Mahasarakham University, Maha Sarakham, Thailand 44150

E-mail: pawitra.p@msu.ac.th

Mobile Phone: (66)-87-589-1543

Current Position: Associate Professor, Faculty of Pharmacy, Mahasarakham University, Thailand

Area of interest: Pharmacology of the endocrine system, Biological activity of medicinal plants and natural products

\section{Education:}

2009: Ph.D. (Physiology and Pharmacology), School of Biomedical Sciences, The University of Nottingham, UK

2001: M.Sc. in Pharmacy (Pharmacology), Faculty of Pharmacy, Mahidol University, Thailand

1999: B. Pharm (1 ${ }^{\text {st }}$ Honorary), Faculty of Pharmacy, Chiang Mai University, Thailand

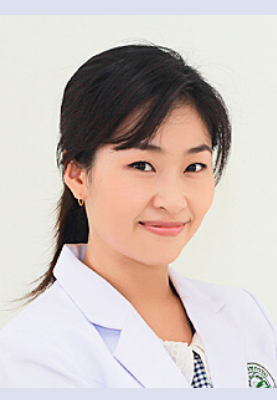

\section{Name: Wanwisa Khunawattanakul, Ph.D.}

Contact: Faculty of Pharmacy, Mahasarakham University, Maha Sarakham, Thailand 44150

E-mail: wanwisa.k@msu.ac.th

Mobile Phone: (66)-81-369-4814

Current Position: Assistant Professor, Faculty of Pharmacy, Mahasarakham University, Thailand

Area of interest: Formulation development, Solid state characterization

\section{Education:}

2011: Ph.D. (Research and development in pharmaceuticals), Faculty of Pharmacy, Khon Kaen University, Thailand

2005: B.Sc. in Pharm ( $1^{\text {st }}$ Honorary), Faculty of Pharmacy, Khon Kaen University, Thailand

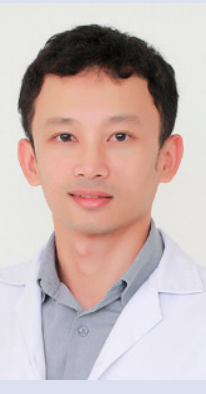

\section{Name: Bunleu Sungthong, Ph.D.}

Contact: Faculty of Pharmacy, Mahasarakham University, Maha Sarakham, Thailand 44150

E-mail: bunleu.s@msu.ac.th

Mobile Phone: (66) 84-597-2464

Current Position: Assistant Professor, Faculty of Pharmacy, Mahasarakham University, Thailand

Area of interest: Medicinal plant researches focusing on analysis of plant secondary metabolites and their biological activity assays

\section{Education:}

2010: Doktor der Naturwissenschaften (Pharmazie), Friedrich-Schiller-University, Germany 2003: M.Pharm. (Pharmaceuticals), Faculty of Pharmaceutical Sciences, Khon Kaen University, Thailand

1998: B.Sc. in Pharm, Faculty of Pharmaceutical Sciences, Khon Kaen University, Thailand 


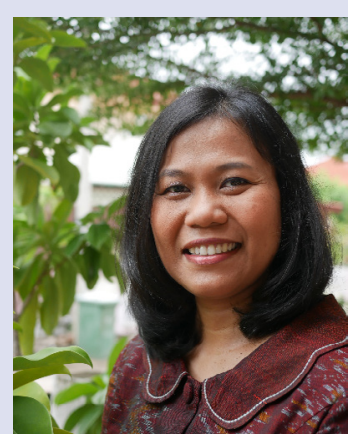

\section{Name: Kritsanee Saramunee, Ph.D.}

Contact: Faculty of Pharmacy, Mahasarakham University, Maha Sarakham, Thailand 44150

E-mail: kritsanee.s@msu.ac.th

Mobile Phone: (66) 81-766-6964

Current Position: Assistant Professor, Faculty of Pharmacy, Mahasarakham University, Thailand

Area of interest: Primary care pharmacy, Public health pharmacy, Drug system management, Research methodology

\section{Education:}

2013: Ph.D. (Pharmacy Practice), Liverpool John Moores University University, UK

2006: M.Sc. (Health Product Management), Khon Kaen University, Thailand

2002: B.Sc. in Pharm, Prince of Songkla University, Thailand

Cite this article: Rattanakiat S, Pulbutr P, Khunawattanakul W, Sungthong B, Saramunee K. Prebiotic Activity of Polysaccharides Extracted from Jerusalem Artichoke Tuber and Development of Prebiotic Granules. Pharmacogn J. 2020;12(6):1402-11. 